\title{
Neural Encoding of Psychomotor Activation in the Nucleus Accumbens Core, But Not the Shell, Requires Cannabinoid Receptor Signaling
}

\author{
Joshua T. Morra, ${ }^{1}$ Stanley D. Glick, ${ }^{1}$ and Joseph F. Cheer ${ }^{2}$ \\ ${ }^{1}$ Center for Neuropharmacology and Neuroscience, Albany Medical College, Albany, New York 12208, and ${ }^{2}$ Department of Anatomy and Neurobiology, \\ University of Maryland School of Medicine, Baltimore, Maryland 21201
}

The current study aimed to further elucidate the role of endocannabinoid signaling in methamphetamine-induced psychomotor activation. Rats were treated with bilateral, intracranial microinjections of the cannabinoid CB1 receptor antagonists rimonabant $(1 \mu \mathrm{g} ; 1 \mu \mathrm{l})$ or AM251 ( $1 \mu \mathrm{g} ; 1 \mu \mathrm{l})$, or vehicle $(1 \mu \mathrm{l})$, followed by intravenous methamphetamine $(3 \mathrm{mg} / \mathrm{kg})$. Antagonist pretreatment in the nucleus accumbens core, but not shell, attenuated methamphetamine-induced stereotypy, while treatment in either brain region had no effect on drug-induced locomotion. In a parallel experiment, we recorded multiple single units in the nucleus accumbens of behaving rats treated with intravenous rimonabant $(0.3 \mathrm{mg} / \mathrm{kg})$ or vehicle, followed by methamphetamine $(0.01,0.1,1,3 \mathrm{mg} / \mathrm{kg}$; cumulative dosing). We observed robust, phasic changes in neuronal firing time locked to the onset of methamphetamine-induced locomotion and stereotypy. Stereotypy encoding was observed in the core and was attenuated by CB1 receptor antagonism, while locomotor correlates were observed uniformly across the accumbens and were not affected by rimonabant. Psychomotor activation encoding was expressed predominantly by putative fast-spiking interneurons. We therefore propose that endocannabinoid modulation of psychomotor activation is preferentially driven by CB1 receptor-dependent interneuron activity in the nucleus accumbens core.

\section{Introduction}

Endocannabinoids (eCBs) are endogenous counterparts to $\Delta^{9}$ tetrahydrocannabinol, the primary psychoactive constituent of Cannabis sativa. Cannabinoid ligands exert their effects on the CNS by binding to $\mathrm{G}_{\mathrm{i} / \mathrm{o}}$-coupled cannabinoid (CB1) receptors (Matsuda et al., 1990). Following their synthesis and release from postsynaptic membranes, eCBs stimulate presynaptic CB1 receptors, thereby attenuating subsequent neurotransmitter release (Piomelli, 2003).

Behaviors related to psychostimulant abuse have been of particular interest in recent eCB research (Wiskerke et al., 2008). Psychomotor activation is a behavioral index of stimulant psychopharmacology characterized by augmented locomotion and stereotyped behaviors (stereotypy). Diminished psychomotor activation has been observed in CB1 knock-out mice and rodents treated with cannabinoid antagonists (Corbillé et al., 2007). These deficits are accompanied by abated drug-induced phasic dopamine release events (Cheer et al., 2007) and extracellular

Received 0ct. 28, 2009; revised Feb. 16, 2010; accepted March 9, 2010.

This research was funded by National Institutes of Health Grants 1F30DA026258-01 (J.T.M.) and R01DA25890 (J.F.C.). We thank Joseph E. Mazurkiewicz and Marilyn Dockum for their assistance and technical expertise regarding histological methods. We also thank Joshua D. Berke for his helpful discussion regarding electrophysiological data analysis.

Correspondence should be addressed to either of the following: Joshua T. Morra, $47 \mathrm{New}$ Scotland Avenue (MC: 136), Center for Neuropharmacology and Neuroscience, Albany Medical College, Albany, NY 12208, E-mail: morraj@mail.amc.edu; or Joseph F. Cheer, Department of Anatomy and Neurobiology, University of Maryland School of Medicine, 20 Penn Street, Baltimore, MD 21201, E-mail: jchee001@umaryland.edu.

DOI:10.1523/JNEUROSCI.5335-09.2010

Copyright $\odot 2010$ the authors $\quad 0270-6474 / 10 / 305102-06 \$ 15.00 / 0$ signal-regulated kinase (ERK 1/2) phosphorylation (Corbillé et al., 2007) in the nucleus accumbens (NAc), implicating this brain region as a crucial neuroanatomical substrate of $\mathrm{eCB}$ modulation of psychomotor activation.

The current study aimed to further elucidate the role of NAc eCB transmission in psychomotor activation. We show that local signaling at NAc CB1 receptors mediates methamphetamineinduced stereotypy, but not locomotion. Additionally, we demonstrate that robust, phasic electrophysiological correlates of psychomotor activation exist in the NAc of behaving rats. Stereotypy correlates are shown to require $\mathrm{CB} 1$ receptor signaling, while locomotion encoding is CB1 receptor independent. Finally, we propose that NAc fast-spiking interneurons (FSIs) preferentially mediate these phenomena.

\section{Materials and Methods}

Animals and surgery. Male Sprague Dawley rats implanted with jugular vein catheters were individually housed in a $12 \mathrm{~h}$ light/dark environment ( $n=46 ; 300-400 \mathrm{~g}$; Charles River). Microinjection subjects were surgically prepared $72 \mathrm{~h}$ before experiments. Guide cannulae (BAS) were stereotaxically implanted bilaterally into the NAc core $( \pm 1.4 \mathrm{~mm}$ lateral, 1.6 $\mathrm{mm}$ anterior, $6.8 \mathrm{~mm}$ ventral from bregma), NAc shell ( $\pm 0.7 \mathrm{~mm}$ lateral, $1.6 \mathrm{~mm}$ anterior, $7.2 \mathrm{~mm}$ ventral from bregma), or dorsal striatum $( \pm 2.0$ $\mathrm{mm}$ lateral, $1.6 \mathrm{~mm}$ anterior, $4.7 \mathrm{~mm}$ ventral from bregma). Electrophysiology subjects were surgically prepared 1 week before experiments. Rats were stereotaxically implanted with unilateral, stainless steel, $8 \times 2$ microwire arrays $(0.25 \mathrm{~mm}$ interelectrode space, $0.5 \mathrm{~mm}$ inter-row space; Micro Probe) such that lateral electrode tips were arranged caudorostrally in the NAc core $(+1.25 \mathrm{~mm}$ lateral, $0.6-2.35 \mathrm{~mm}$ anterior, $7.2 \mathrm{~mm}$ ventral from bregma), and medial electrode tips were arranged caudor- 


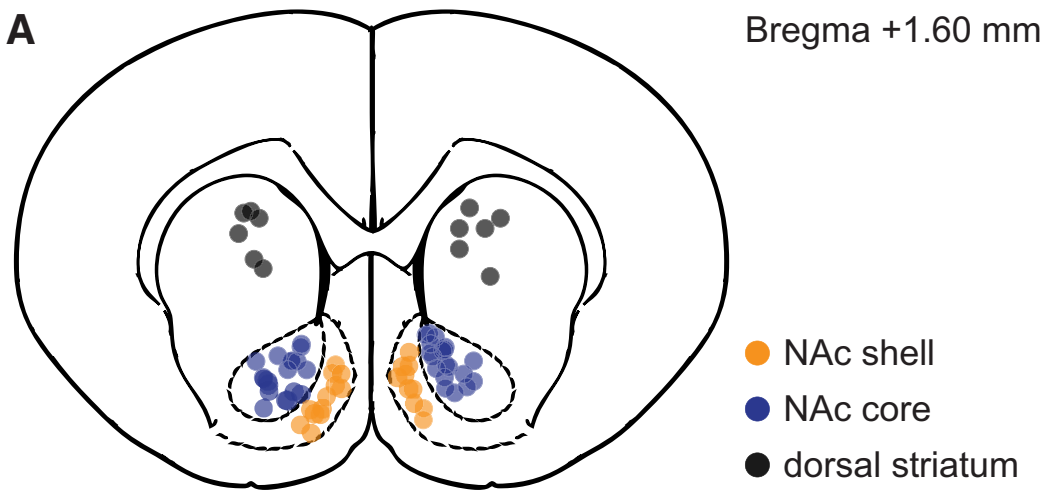

B

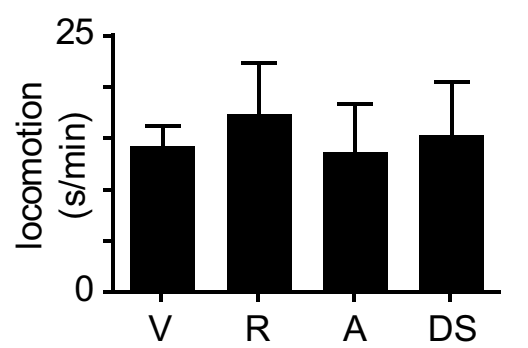

(6)

(6)

(6) (6)
C

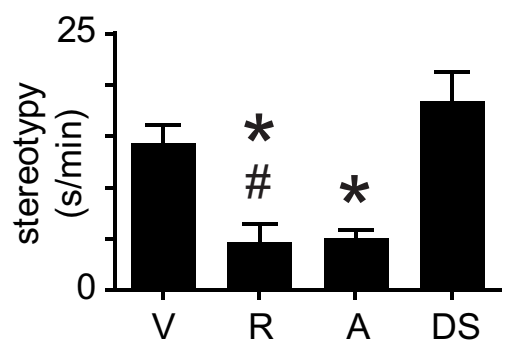

(6)
(6) (6)

Figure 1. NAC CB1 receptor antagonism attenuates stereotypy, but not locomotion. $\boldsymbol{A}$, Coronal schematic depicting core, shell, and dorsal striatum microinjection sites. $\boldsymbol{B}$, Time spent in locomotion following methamphetamine ( $3 \mathrm{mg} / \mathrm{kg}$; i.v.) for core-microinjected subjects pretreated with bilateral vehicle $(V)$, rimonabant $(R ; 1 \mu \mathrm{g})$, or $A M 251(A ; 1 \mu \mathrm{g})$ and dorsal striatum-microinjected subjects pretreated with rimonabant (DS; $1 \mu \mathrm{g}$ ). C, Time spent in stereotypy following methamphetamine for core- and dorsal striatum-microinjected subjects. Both rimonabant and AM251 attenuate stereotypy ( ${ }^{*} p<0.05$ compared to vehicle). Subjects given core rimonabant express less stereotypy than subjects given dorsal striatum rimonabant $\left({ }^{\#} p<0.01\right)$.

ostrally in the shell $(+0.75 \mathrm{~mm}$ lateral, $0.6-2.35 \mathrm{~mm}$ anterior, $7.2 \mathrm{~mm}$ ventral from bregma).

Multiple single-unit recordings. Multiunit signals were referenced to ground, amplified, filtered, and sorted from noise as previously described (Mason and Cheer, 2009). Offline spike sorting was performed using a multivariate $t$-distribution algorithm (Shoham et al., 2003) with a 2 SD outlier threshold (Offline Sorter; Plexon), followed by manual confirmation of sorting validity.

Neuron classification. Neurons were manually sorted based on waveform shape and firing rate (see Fig. 3E). A subpopulation of neurons met previously established criteria for FSIs (Berke et al., 2004). Both the prevalence (12\% of all units) and distribution (59\% recorded on lateral electrodes) of FSIs matched previously reported values (Berke et al., 2004). Neurons with slow waveform shapes (peak widths $>120 \mu$ s; valley widths $>265 \mu$ s) and low firing rates $(<5 \mathrm{~Hz})$ were presumed to be medium spiny neurons (MSNs).

Dosing regimen. Microinjection subjects were habituated for $1 \mathrm{~h}$ to a chamber equipped with a commutator to allow intravenous drug administration during on-going behavior (Med Associates). Subjects were then given bilateral, intracranial microinfusions of rimonabant $(1 \mu \mathrm{g} ; 1 \mu \mathrm{l}$; shell, $n=6$; core, $n=6$; dorsal striatum, $n=6$ ), AM251 ( $1 \mu \mathrm{g} ; 1 \mu \mathrm{l}$; core, $n=6)$, or vehicle ( $1 \mu \mathrm{l}$; shell, $n=6$; core, $n=6$ ) followed by intravenous methamphetamine $(3 \mathrm{mg} / \mathrm{kg})$. Animals were then permitted to behave freely until psychomotor activation subsided $(\sim 3-6 \mathrm{~h})$.

Electrophysiology subjects were habituated as previously described, followed by $20 \mathrm{~min}$ of baseline recording. Subjects were then given intravenous vehicle (animals, $n=5$; neurons, $n=64)$, rimonabant $(0.3$ $\mathrm{mg} / \mathrm{kg}$; animals, $n=4$; neurons, $n=54$ ), or no treatment (pilot experiment; animals, $n=1$; neurons, $n=22$ ), followed by saline, followed thereafter by methamphetamine $(0.01,0.1,1,3 \mathrm{mg} / \mathrm{kg}$; cumulative dosing) (5 min interinjection interval). Animals were then permitted to behave freely until psychomotor activation subsided $(\sim 3-6 \mathrm{~h})$.
Histology. Following microinjection experiments, rats were bilaterally microinjected with ink ( $1 \mu \mathrm{l}$; Spaulding Color). Brains were then removed, frozen, and sliced to confirm microinjection placement (Fig. 1A). Following electrophysiological experiments, electrode tip placement was confirmed via previously published methods (Carelli et al., 2000) (Fig. 2A). Units recorded on lateral electrodes were said to be in the core; medial electrode units were said to reside in the shell. Histological misses were excluded from further analysis.

Behavior. All experiments were video recorded (30 frames/s) for offline analysis by an experimenter blinded to treatment. Locomotion and stereotypy were quantified using an all-or-none score (i.e., "present" or "not present"; 1 s bins) for the first 15 min following methamphetamine for microinjection groups, and the first $75 \mathrm{~min}$ for electrophysiology experiments. Locomotion was defined as the continuous, forward propulsion of the subject's center of gravity during which all four of the animal's paws perform at least one step. Locomotion was said to begin at the onset of the first paw step and end at the cessation of the last paw step. Stereotypy was defined as the simultaneous presence of three criteria: (1) all four of the animal's paws are stationary, (2) excessive sniffing $(\sim 10 \mathrm{~Hz})$, and $(3)$ at least three rhythmic head bobs $(\sim 4-8 \mathrm{~Hz})$. Stereotypy was said to begin at the onset of the first head bob and end upon the cessation of any of the three defined criteria. This strict definition of stereotypy ensured that electrophysiological analyses time locked to the onset of stereotypy would be uncontaminated by aspects of locomotor neural encoding, and would instead be clamped to a consistent, non-overlapping behavior.

The onset of each behavioral bout was determined by manual, frameby-frame video inspection. Video timestamps were then compared to changes in the subjects' $x-y$ coordinate space location, as determined via automated software (24 Hz sampling rate; Cineplex; Plexon). Slight disparities between visual scoring and automated tracking were sometimes observed due to inherent differences in sampling frequency (mean discrepancy $=12 \mathrm{~ms}$ ). If timestamp differences were observed consistently across all trials, a correction was applied to all timestamps for that experiment.

Data analysis. Bar graphs, line graphs, and two-dimensional scatter plot construction and all statistical analyses were performed using GraphPad Prism (GraphPad Software). Firing rate, perievent, and interspike interval histograms were constructed using NeuroExplorer (Nex Technologies). Three-dimensional scatter plots were created using MATLAB (The MathWorks). Spike shape displays were created using Offline Sorter (Plexon). Statistical comparisons were performed using standard unpaired $t$ tests, or one- and two-way ANOVAs, followed by Tukey's multiple-comparison test. Population normality was tested using the D'Agostino-Pearson normality test. The criterion for significance was set at $p<0.05$. All error bars represent \pm SEM. Locomotion/electrophysiology correlation analyses were restricted to time bins following 0.1 and/or $1 \mathrm{mg} / \mathrm{kg}$ methamphetamine because these doses induced robust locomotion with minimal stereotypy confounds (Fig. 2D,E). Conversely, stereotypy/electrophysiology correlation analyses were restricted to time bins following $3 \mathrm{mg} / \mathrm{kg}$ METH.

Drugs. Methamphetamine (Sigma-Aldrich) was delivered in saline. Rimonabant (SR141716A; Research Triangle Institute-National Institute on Drug Abuse) and AM251 (Tocris Bioscience) were delivered in dimethyl sulfoxide for microinjections and a 1:1:18 ratio of ethanol, Emulphor, and saline for intravenous injections. 
A

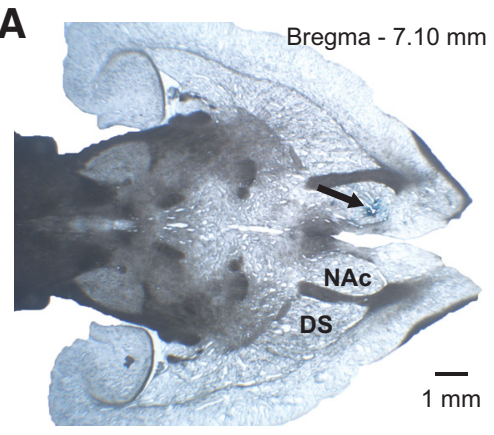

C
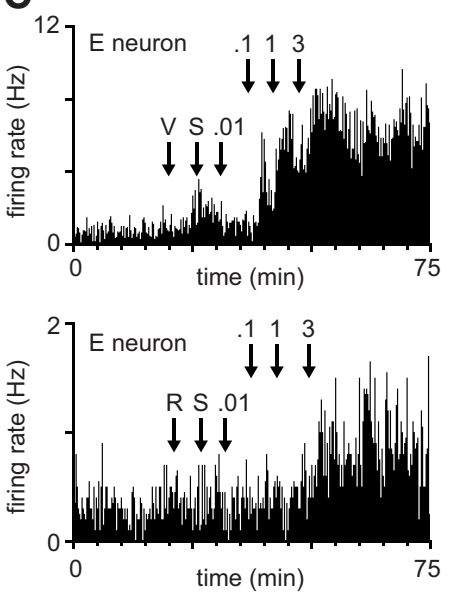

time $(\min )$
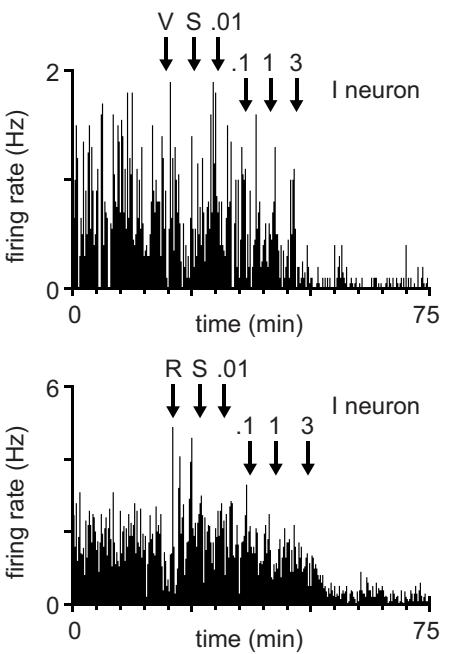

$\mathbf{F}$

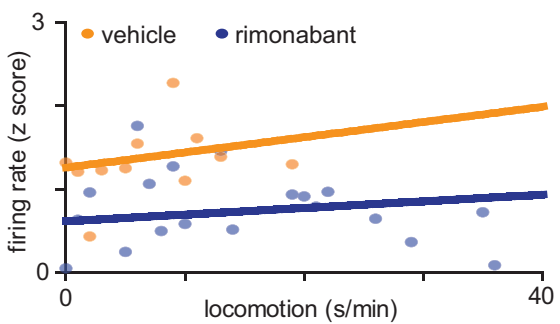

D

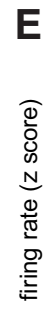
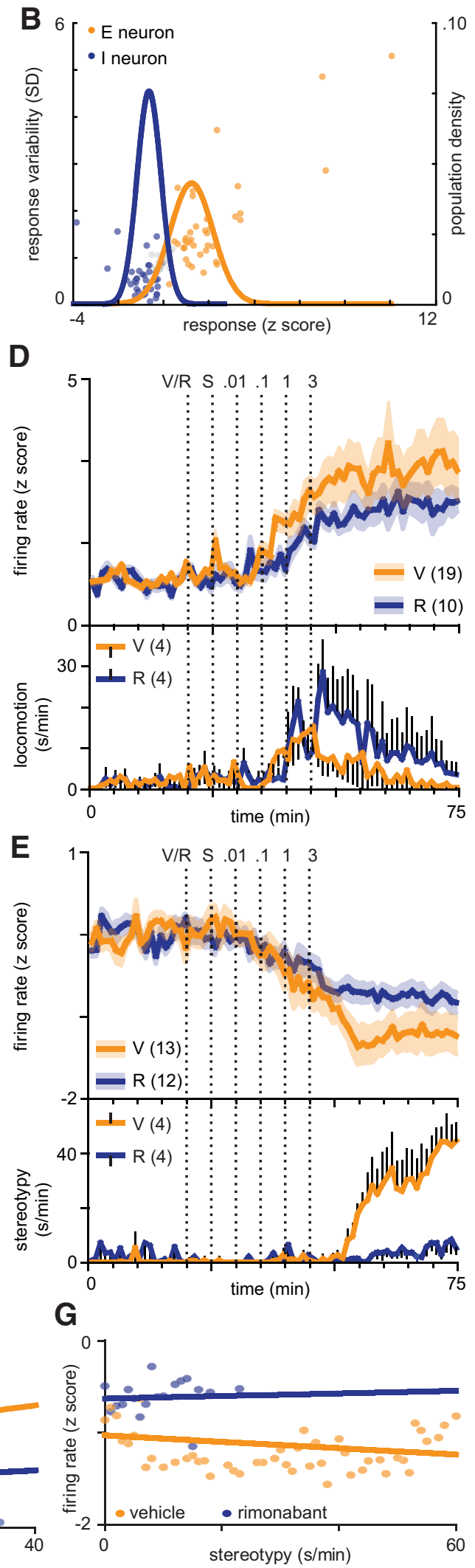

Figure 2. Tonic NAc firing rates do not correlate with psychomotor activation. $\boldsymbol{A}$, Representative horizontal brain slice showing placement of an electrode tip. $\boldsymbol{B}$, Methamphetamine induces a bimodal response distribution (E neurons, firing rate $>125 \%$ baseline, or firing rate $>100 \%$ baseline and firing rate variability $>125 \%$ baseline; I neurons, firing rate $<75 \%$ baseline, or firing rate $<100 \%$ baseline and firing rate variability $<75 \%$ baseline). Unresponsive neurons (firing rate between $75 \%$ and $125 \%$ and firing rate variability between $75 \%$ and $125 \%$ baseline) are plotted in gray. C, Representative firing rate histograms of example $E$ and I neurons in vehicle- and rimonabant-treated subjects (10 s bins). Arrows indicate time of vehicle/rimonabant $(0.3 \mathrm{mg} / \mathrm{kg} ; \mathrm{i.v}$.), saline, and methamphetamine $(0.01,0.1,1,3 \mathrm{mg} / \mathrm{kg}$; i.v.) administration. $\boldsymbol{D}$, Mean E neuron firing rates across time

\section{Results}

Stereotypy, but not locomotion, requires $\mathrm{CB} 1$ receptor signaling in the NAc core

We performed a series of microinjection experiments to determine whether psychomotor activation requires NAc CB1 receptor signaling. Rats received bilateral, intracranial microinfusions of vehicle, rimonabant $(1 \mu \mathrm{g})$, or AM251 (1 $\mu \mathrm{g})$ into either the NAc core or shell, followed by intravenous methamphetamine $(3 \mathrm{mg} / \mathrm{kg})$. Shell treatment had no effect on methamphetamine-induced locomotion (data not shown; unpaired $t$ test, $\left.t_{(10)}=0.01, p>0.05\right)$ or stereotypy (data not shown; unpaired $t$ test, $t_{(10)}=$ $0.52, p>0.05)$. However, drug application in the core attenuated methamphetamineinduced stereotypy (Fig. 1C) (one-way ANOVA, $F_{(3,23)}=12.52, p<0.001$; rimonabant vs vehicle, Tukey's multiplecomparisons test, $p<0.05$; AM251 vs vehicle, Tukey's multiple-comparisons test, $p<0.05$ ), but not locomotion (Fig. $1 B$ ) (one-way ANOVA, $F_{(3,23)}=0.14, p>$ $0.05)$. Anatomic specificity of this effect was confirmed by an additional group of rats that received rimonabant infusions into the dorsal striatum followed by methamphetamine (Fig. 1C) (core rimonabant vs dorsal striatum rimonabant, Tukey's multiple-comparisons test, $p<0.01$ ).

\section{Methamphetamine heterogeneously affects NAc firing rates}

Local pharmacological manipulation of the NAc was sufficient to modulate stereotypy; therefore, we investigated methamphetamine's electrophysiological effects in the NAc. We recorded NAc multiple single-unit activity in rats given intravenous vehicle or rimonabant $(0.3 \mathrm{mg} / \mathrm{kg})$, followed by saline, followed thereafter by methamphetamine $(0.01,0.1,1,3 \mathrm{mg} / \mathrm{kg}$; cumulative dosing). A subpopulation of neurons were responsive to methamphetamine $(86 / 139,61.9 \%)$. Units responsive to saline or expressing biphasic methamphetamine responses were excluded from further analysis. The remaining units followed a bimodal distribution, and were

(60 $\mathrm{s}$ bins; top). Methamphetamine increases $\mathrm{E}$ neuron firing rates. Mean time spent in locomotion across time $(60 \mathrm{~s}$ bins; bottom). $\boldsymbol{E}$, Mean I neuron firing rates across time ( $60 \mathrm{~s}$ bins; top). Methamphetamine decreases I neuron firing rates. Rimonabant attenuates this effect. Mean time spent in stereotypy across time ( $60 \mathrm{~s}$ bins; bottom). Methamphetamine increases stereotypy. Rimonabant attenuates this effect. $\boldsymbol{F}$, Linear regression of $E$ neuron firing rates as a function of locomotion (60 s bins). G, Linear regression of I neuron firing rates as a function of stereotypy (60 $\mathrm{s}$ bins). 
characterized as either methamphetamine-excited (E neurons; Gaussian fit, $R^{2}=0.46$; normality of residuals, $p<0.001$ ) or methamphetamine-inhibited (I neurons; Gaussian fit, $R^{2}=0.49$; normality of residuals, $p<0.001$ ) neurons (Fig. $2 B, C$ ). No core/ shell differences in E/I neuron activity were observed (data not shown; E neurons, one-way ANOVA, $F_{(1,25)}=0.86, p>0.05$; I neurons, one-way ANOVA, $\left.F_{(1,23)}=0.20, p>0.05\right)$. Therefore, $\mathrm{E}$ and I populations were pooled across brain regions for further analysis. Methamphetamine increased $\mathrm{E}$ neuron firing rates (one-way ANOVA, $F_{(74,1850)}=18.00, p<0.001$ ) and decreased I neuron firing rates (one-way ANOVA, $F_{(74,1850)}=$ 21.50, $p<0.001)$.

\section{Tonic NAc firing rates do not correlate with} psychomotor activation

Rimonabant alone had no effect on $\mathrm{E}$ (one-way ANOVA, $F_{(1,27)}=$ $1.49, p>0.05)$ or I (one-way ANOVA, $F_{(1,23)}=3.46, p>0.05$ ) neuron activity. However, rimonabant attenuated methamphetamine-induced changes in I (two-way ANOVA, $F_{(74,1702)}=1.99, p<$ 0.001 ), but not $\mathrm{E}$ (two-way ANOVA, $F_{(74,1998)}=1.12, p>0.05$ ) tonic firing (Fig. 2D,E, top). Additionally, rimonabant attenuated methamphetamine-induced stereotypy (two-way ANOVA, $F_{(74,444)}=7.26, p<0.001$ ), but not locomotion (two-way ANOVA, $F_{(74,444)}=1.06, p>0.05$ ) (Fig. $2 D, E$, bottom). We therefore hypothesized that functional E neuron/locomotion and I neuron/stereotypy relationships exist. No core/shell differences in activity/behavior correlations were observed (data not shown; E neuron/locomotion, linear regression, $F_{(3,172)}=0.30, p>0.05$; I neuron/stereotypy, linear regression, $\left.F_{(3,717)}=2.02, p>0.05\right)$. Therefore, neurons were pooled across anatomic regions for further analysis. Neither E nor I tonic activity correlated with methamphetamine-induced locomotion (Fig. $2 F)$ (vehicle, $R^{2}=$ $0.10, p>0.05$; rimonabant, $R^{2}=0.03, p>0.05$ ) or stereotypy (Fig. $2 G$ ) (vehicle, $R^{2}=0.01, p>0.05$; rimonabant, $R^{2}=0.02$, $p>0.05)$, respectively.

\section{Rimonabant attenuates phasic correlates of stereotypy, but} not locomotion

In contrast with tonic activity, phasic firing patterns were time locked to the onset of locomotion and stereotypy (Fig. 3A). Locomotion encoding was expressed uniformly across the NAc core and shell (data not shown; unpaired $t$ test, $t_{(23)}=0.30, p>0.05$ ). Responses from both brain regions were therefore pooled for further analysis. Conversely, although individual neurons in both brain regions expressed phasic stereotypy correlates, mean population activity in the core (Fig. 3C), but not the shell (Fig. 3D), expressed stereotypy encoding. Rimonabant attenuated phasic correlates of methamphetamine-induced stereotypy (Fig. 3C) (unpaired $t$ test, $t_{(15)}=2.20, p<0.05$ ), but not locomotion (Fig. $3 B$ ) (unpaired $t$ test, $t_{(23)}=0.37, p>0.05$ ).

\section{FSIs preferentially encode psychomotor activation}

To determine whether a subpopulation of neurons preferentially encode psychomotor activation, we classified units based on waveform shape and firing rate (Fig. $3 E$ ). A disproportionate percentage of FSIs (locomotion, 41.2\%; stereotypy, 70.6\%) expressed psychomotor activation encoding, as compared to MSNs (locomotion 18.6\%; stereotypy 18.6\%) (Fig. 3F). Rimonabant did not differentially affect MSN or FSI encoding strength (data not shown; two-way ANOVA, $\left.F_{(1,10)}=0.03, p>0.05\right)$. Additionally, the majority of FSIs were found in the NAc core $(58.8 \%)$.
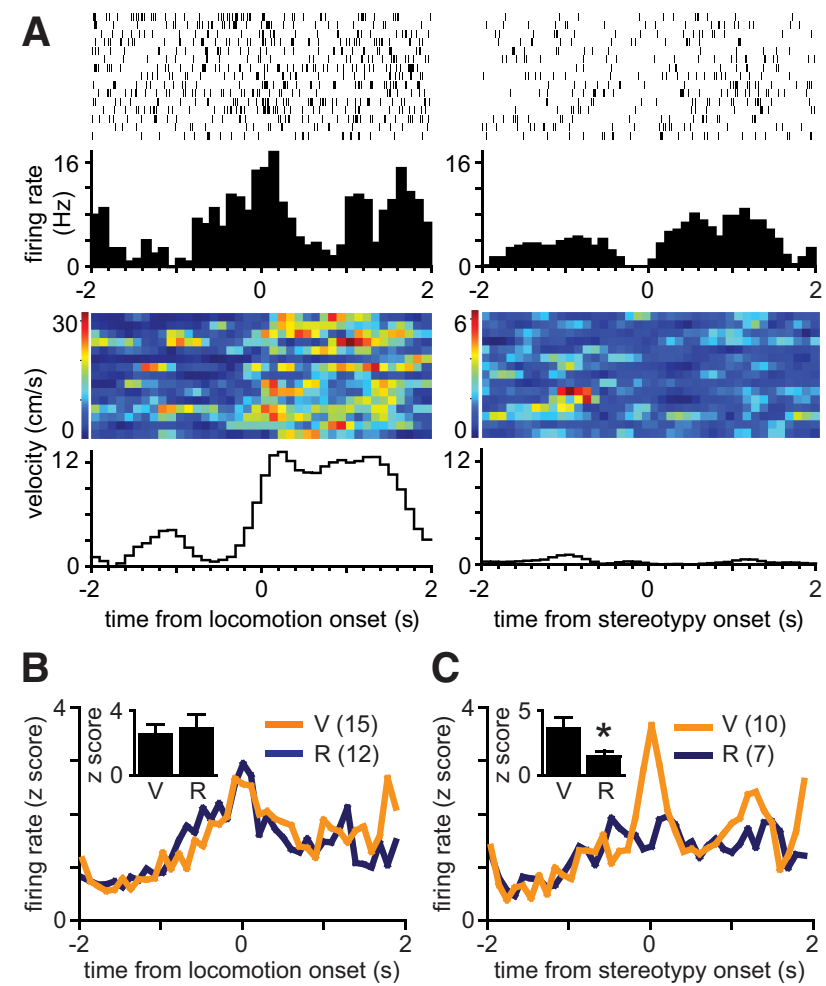

D

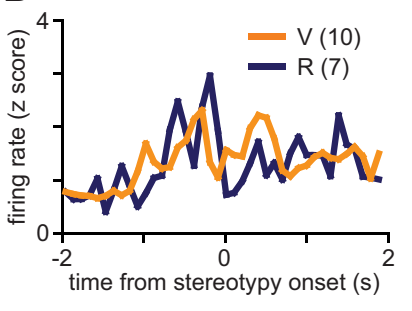

\section{E}
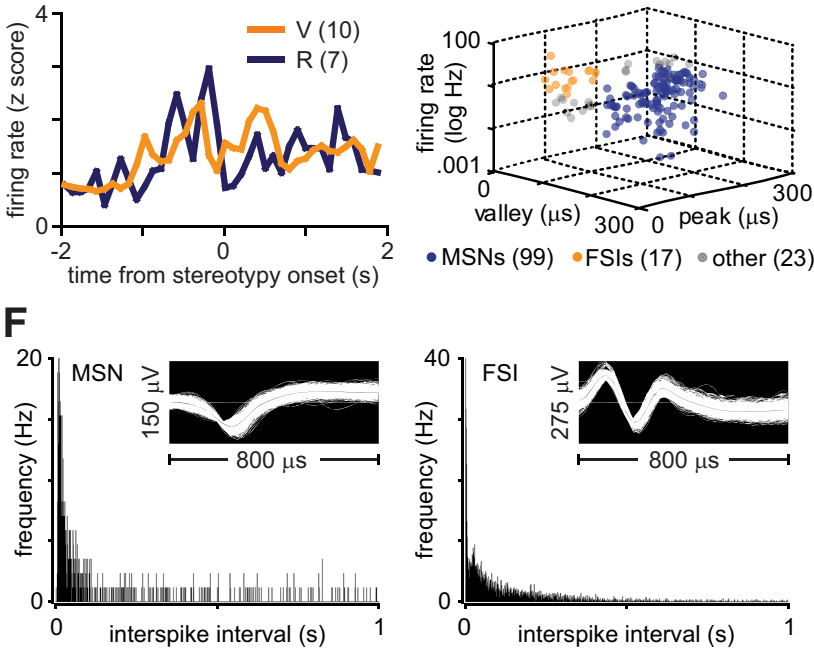

\begin{tabular}{|l|c|c|}
\hline putative neuron classification & MSNs & FSIs \\
\hline mean firing rate $(\mathrm{Hz})$ & $1.1(+/-0.1)$ & $13.3(+/-4.0)$ \\
\hline mean valley width $(\mu \mathrm{s})$ & $184.9(+/-3.2)$ & $119.5(+/-6.7)$ \\
\hline mean peak width $(\mu \mathrm{s})$ & $245.1(+/-5.9)$ & $136.0(+/-6.3)$ \\
\hline$\%$ locomotion encoding & 18.6 & 41.2 \\
\hline$\%$ stereotypy encoding & 18.6 & 70.6 \\
\hline
\end{tabular}

Figure 3. CB1 receptor antagonism attenuates NAc encoding of stereotypy, but not locomotion. $\boldsymbol{A}$, Representative perievent histogram and raster plot of a neuron phasically excited at the onset of locomotion (left) and inhibited at the onset of stereotypy (right). The subject's perievent velocity is represented in color scale (bottom). $\boldsymbol{B}$, Mean perievent firing rates of NAc neurons encoding locomotion ( $z$ score absolute value). $C$, Mean perievent firing rates of core neurons encoding stereotypy (zscore absolute value). Rimonabant attenuates stereotypy encoding $\left({ }^{*} p<0.05\right)$. D, Mean perievent firing rates of shell neurons encoding stereotypy (z score absolute value). $\boldsymbol{E}$, Scatter plot of firing rates as a function of waveform shape. $\boldsymbol{F}$, Interspike interval histograms and waveform shapes for a representative MSN (left) and FSI (right). A disproportionate percentage of FSIs exhibit psychomotor activation encoding (bottom). 


\section{Discussion}

Previous reports suggest that $\mathrm{eCB}$ modulation of psychomotor activation can only be understood when framed in the proper genetic and pharmacological context. Genetic inactivation of the CB1 receptor has no effect on psychostimulant-induced locomotion in mice with a CD1 genetic background (Martin et al., 2000; Corbillé et al., 2007; Thiemann et al., 2008a). However, CB1 knock-out mice with a C57BL/6 genetic background express diminished drug locomotor responses (Houchi et al., 2005; Thiemann et al., 2008b). Despite genetically variable CB1 knockout manifestations, AM251 consistently has no effect on druginduced locomotion across multiple genetic backgrounds (Landa et al., 2006; Corbillé et al., 2007; Thiemann et al., 2008a). This suggests that although compensatory neural responses to CB1 genetic invalidation vary between animal strains, acute CB1 antagonism invariably has no locomotor effect.

Published rimonabant results are more difficult to reconcile. Augmented (Masserano et al., 1999; Thiemann et al., 2008b), attenuated (Tzavara et al., 2003; Cheer et al., 2007; Tzavara et al., 2009), and unaltered (Lesscher et al., 2005; Gerdeman et al., 2008) drug locomotor responses have all been reported in rimonabant-treated rodents of varying genetic backgrounds. This apparent contradiction is resolved when drug dose size is considered. Rimonabant consistently has no locomotor effect following a low-dose psychostimulant challenge (Lesscher et al., 2005; Gerdeman et al., 2008), while higher doses capable of inducing stereotypy (Kuczenski et al., 1991) produce highly variable results (Masserano et al., 1999; Tzavara et al., 2003, 2009; Cheer et al., 2007; Thiemann et al., 2008b). This suggests that rimonabant's apparent locomotor effects are an epiphenomenon of its primary stereotypy effects.

Our results affirm this assertion. We show that neither rimonabant nor AM251 affect methamphetamine-induced locomotion; yet both antagonists block stereotypy. Furthermore, we show that the NAc is a crucial neuroanatomical substrate for this interaction. Previous literature suggests that local application of the CB1 receptor antagonist SR147778 has no effect on methamphetamine-induced stereotypy (Chiang and Chen, 2007); however, this study used local CB1 receptor antagonism in the NAc shell. Our results both confirm and expand upon this finding, by showing that $\mathrm{CB} 1$ receptor blockade in the core, but not the shell, attenuates stereotypy.

These findings shed new light upon traditional psychomotor activation neuroanatomical concepts. Generally accepted theory states that psychostimulant-induced locomotion is driven by the ventral striatum, while stereotypy substrates are localized in the dorsal striatum. This hypothesis is primarily derived from 6-hydroxydopamine lesion studies demonstrating that local dopamine depletion in the ventral striatum inhibits amphetamineinduced locomotion, while dorsal lesions curb stereotypy (Robbins and Iversen, 1973; Creese and Iversen, 1974; Kelly et al., 1975). However, this does not preclude the possibility that stereotypy may also recruit nondopaminergic substrates in the NAc.

This possibility gains merit when one considers that reductions in CB1 receptor signaling block stereotypy, but leave tonic striatal dopamine levels unscathed following a methamphetamine challenge (Tzavara et al., 2009). Pretreatment with a metabotropic glutamate receptor-5 (mGluR5) antagonist occludes this effect (Tzavara et al., 2009), suggesting that eCB modulation of stereotypy is glutamate-, rather than DA-, dependent. Furthermore, methamphetamine has been shown to increase glutamate efflux in the core (Zhang et al., 2001), but not in the shell (Shoblock et al., 2003) or dorsal striatum (Zhang et al., 2001). Considered alongside our results, this suggests that stereotypy may be driven by eCB tuning of methamphetamine-induced glutamate release in the core (Pistis et al., 2002; Adermark et al., 2009).

By extension, our electrophysiological findings may be a reflection of this process. We show that methamphetamine has heterogeneous effects on tonic firing rates in the NAc. Importantly, rimonabant blocks nearly all stereotypy, yet its effect on tonic firing is modest. Furthermore, methamphetamine-induced changes in behavior and tonic neural activity are temporally independent of one another, suggesting that tonic NAc activity and psychomotor activation are not causally linked.

In contrast, phasic NAc firing patterns are exquisitely time locked to the onset of methamphetamine-induced locomotion and stereotypy. While locomotor correlates were observed uniformly throughout the NAc, stereotypy correlates are expressed solely in the core. Additionally, rimonabant blocks stereotypy, but not locomotion, encoding. These electrophysiological findings precisely mirror our microinjection behavioral data, implying that phasic changes in NAc activity may be causally linked to psychomotor activation. This possibility is substantiated by the observation that phasic correlates of locomotion and stereotypy begin $\sim 250$ ms before the onset of each behavioral bout.

Phasic behavioral encoding was predominantly observed in FSIs, suggesting that striatal FSIs are the primary neuronal population responsible for mediating psychomotor activation. Previous work supports this argument. Striatal gamma local field potential oscillations are hypothesized to be driven by coordinated FSI activity (Berke et al., 2004). Low gamma $(\sim 50 \mathrm{~Hz})$ events have been shown to temporally coincide with movement initiation (Masimore et al., 2005), while high gamma ( 80-100 $\mathrm{Hz}$ ) oscillations are augmented following doses of amphetamine capable of stereotypy induction (Berke, 2009). Furthermore, striatal mGluR5s (aforementioned to be crucial to eCB modulation of psychomotor activation) are preferentially expressed by FSIs (Tallaksen-Greene et al., 1998; Mitrano and Smith, 2007). mGluR5 overexpression may render FSIs uniquely sensitive to methamphetamine-induced glutamate release in the NAc core (Zhang et al., 2001). Augmented afferent glutamate transmission may serve to induce mGluR5-dependent eCB release from FSIs; eCBs could then phasically inhibit subsequent, presynaptic glutamate and GABA release (Adermark et al., 2009) onto FSIs. Such a mechanism could provide an appropriate temporal sequence for neural encoding of stereotypy, and account for the FSIspecific nature of this phenomenon.

\section{References}

Adermark L, Talani G, Lovinger DM (2009) Endocannabinoid-dependent plasticity at GABAergic and glutamatergic synapses in the striatum is regulated by synaptic activity. Eur J Neurosci 29:32-41.

Berke JD (2009) Fast oscillations in cortical-striatal networks switch frequency following rewarding events and stimulant drugs. Eur J Neurosci 30:848-859.

Berke JD, Okatan M, Skurski J, Eichenbaum HB (2004) Oscillatory entrainment of striatal neurons in freely moving rats. Neuron 43:883-896.

Carelli RM, Ijames SG, Crumling AJ (2000) Evidence that separate neural circuits in the nucleus accumbens encode cocaine versus "natural" (water and food) reward. J Neurosci 20:4255-4266.

Cheer JF, Wassum KM, Sombers LA, Heien ML, Ariansen JL, Aragona BJ, Phillips PE, Wightman RM (2007) Phasic dopamine release evoked by abused substances requires cannabinoid receptor activation. J Neurosci 27:791-795.

Chiang YC, Chen JC (2007) The role of the cannabinoid type 1 receptor and 
down-stream cAMP/DARPP-32 signal in the nucleus accumbens of methamphetamine-sensitized rats. J Neurochem 103:2505-2517.

Corbillé AG, Valjent E, Marsicano G, Ledent C, Lutz B, Hervé D, Girault JA (2007) Role of cannabinoid type 1 receptors in locomotor activity and striatal signaling in response to psychostimulants. J Neurosci 27:6937-6947.

Creese I, Iversen SD (1974) The role of forebrain dopamine systems in amphetamine induced stereotyped behavior in the rat. Psychopharmacologia 39:345-357.

Gerdeman GL, Schechter JB, French ED (2008) Context-specific reversal of cocaine sensitization by the $\mathrm{CB}(1)$ cannabinoid receptor antagonist rimonabant. Neuropsychopharmacology 33:2747-2759.

Houchi H, Babovic D, Pierrefiche O, Ledent C, Daoust M, Naassila M (2005) $\mathrm{CB} 1$ receptor knockout mice display reduced ethanol-induced conditioned place preference and increased striatal dopamine D2 receptors. Neuropsychopharmacology 30:339-349.

Kelly PH, Seviour PW, Iversen SD (1975) Amphetamine and apomorphine responses in the rat following 6-OHDA lesions of the nucleus accumbens septi and corpus striatum. Brain Res 94:507-522.

Kuczenski R, Segal DS, Aizenstein ML (1991) Amphetamine, cocaine, and fencamfamine: relationship between locomotor and stereotypy response profiles and caudate and accumbens dopamine dynamics. J Neurosci 11:2703-2712.

Landa L, Sulcova A, Slais K (2006) Involvement of cannabinoid CB1 and $\mathrm{CB} 2$ receptor activity in the development of behavioural sensitization to methamphetamine effects in mice. Neuro Endocrinol Lett 27:63-69.

Lesscher HM, Hoogveld E, Burbach JP, van Ree JM, Gerrits MA (2005) Endogenous cannabinoids are not involved in cocaine reinforcement and development of cocaine-induced behavioural sensitization. Eur Neuropsychopharmacol 15:31-37.

Martin M, Ledent C, Parmentier M, Maldonado R, Valverde O (2000) Cocaine, but not morphine, induces conditioned place preference and sensitization to locomotor responses in CB1 knockout mice. Eur J Neurosci 12:4038-4046.

Masimore B, Schmitzer-Torbert NC, Kakalios J, Redish AD (2005) Transient striatal gamma local field potentials signal movement initiation in rats. Neuroreport 16:2021-2024.

Mason R, Cheer JF (2009) Cannabinoid receptor activation reverses kainate-induced synchronized population burst firing in rat hippocampus. Front Integr Neurosci 3:13.

Masserano JM, Karoum F, Wyatt RJ (1999) SR 141716A, a CB1 cannabinoid receptor antagonist, potentiates the locomotor stimulant effects of amphetamine and apomorphine. Behav Pharmacol 10:429-432.

Matsuda LA, Lolait SJ, Brownstein MJ, Young AC, Bonner TI (1990) Structure of a cannabinoid receptor and functional expression of the cloned cDNA. Nature 346:561-564.
Mitrano DA, Smith Y (2007) Comparative analysis of the subcellular and subsynaptic localization of mGluR1a and mGluR5 metabotropic glutamate receptors in the shell and core of the nucleus accumbens in rat and monkey. J Comp Neurol 500:788-806.

Piomelli D (2003) The molecular logic of endocannabinoid signalling. Nat Rev Neurosci 4:873-884.

Pistis M, Muntoni AL, Pillolla G, Gessa GL (2002) Cannabinoids inhibit excitatory inputs to neurons in the shell of the nucleus accumbens: an in vivo electrophysiological study. Eur J Neurosci 15:1795-1802.

Robbins T, Iversen SD (1973) A dissociation of the effects of d-amphetamine on locomotor activity and exploration in rats. Psychopharmacologia 28:155-164.

Shoblock JR, Sullivan EB, Maisonneuve IM, Glick SD (2003) Neurochemical and behavioral differences between d-methamphetamine and d-amphetamine in rats. Psychopharmacology 165:359-369.

Shoham S, Fellows MR, Normann RA (2003) Robust, automatic spike sorting using mixtures of multivariate t-distributions. J Neurosci Methods 127:111-122.

Tallaksen-Greene SJ, Kaatz KW, Romano C, Albin RL (1998) Localization of mGluRla-like immunoreactivity and mGluR5-like immunoreactivity in identified populations of striatal neurons. Brain Res 780:210-217.

Thiemann G, Di Marzo V, Molleman A, Hasenöhrl RU (2008a) The CB(1) cannabinoid receptor antagonist AM251 attenuates amphetamineinduced behavioural sensitization while causing monoamine changes in nucleus accumbens and hippocampus. Pharmacol Biochem Behav 89:384-391.

Thiemann G, van der Stelt M, Petrosino S, Molleman A, Di Marzo V, Hasenöhrl RU (2008b) The role of the CB1 cannabinoid receptor and its endogenous ligands, anandamide and 2-arachidonoylglycerol, in amphetamine-induced behavioural sensitization. Behav Brain Res 187:289-296.

Tzavara ET, Davis RJ, Perry KW, Li X, Salhoff C, Bymaster FP, Witkin JM, Nomikos GG (2003) The CB1 receptor antagonist SR141716A selectively increases monoaminergic neurotransmission in the medial prefrontal cortex: implications for therapeutic actions. Br J Pharmacol 138: 544-553.

Tzavara ET, Degroot A, Wade MR, Davis RJ, Nomikos GG (2009) CB1 receptor knockout mice are hyporesponsive to the behavior-stimulating actions of d-amphetamine: role of mGlu5 receptors. Eur Neuropsychopharmacol 19:196-204.

Wiskerke J, Pattij T, Schoffelmeer AN, De Vries TJ (2008) The role of CB1 receptors in psychostimulant addiction. Addict Biol 13:225-238.

Zhang Y, Loonam TM, Noailles PA, Angulo JA (2001) Comparison of cocaine- and methamphetamine-evoked dopamine and glutamate overflow in somatodendritic and terminal field regions of the rat brain during acute, chronic, and early withdrawal conditions. Ann N Y Acad Sci 937: 93-120. 